\title{
Comparing Menarche Age, Menstrual Regularity, Dysmenorrhea and Analgesic Consumption among Athletic and Non-athletic Female Students at Universities of Tabriz-Iran
}

\author{
Hasan Matin Homai ${ }^{1}$, Fahimeh Sehati Shafai ${ }^{2}$, Ladan Zoodfekr ${ }^{3 *}$
}

\begin{abstract}
Objectives: Although sport has many advantages, it sometimes causes disorders on women's menstrual cycles. One of these can be delaying the menarche age and creating disorder in the menstrual cycle. On the other hand, sport is effective on dysmenorrhea and the pain resulted from it. This research aims at comparing the menarche age, menstrual regularity, dysmenorrhea and analgesic consumption among athletic and non-athletic students at the universities of Tabriz.

Materials and Methods: This study is a causal comparative one which was done in 2010 on 360 girl students in 18-28 years old majoring in medicine and non-medicine at the universities of Tabriz. Samples were chosen selectively and completed the questionnaires, visual analogue scale (VAS), sport and menstrual record. The data were analyzed by SPSS 16 statistical software via descriptive and inferential statistical tests (Mann-Whitney $\mathrm{U}$ and Chi-square). $\mathrm{P}<0.05$ was considered as significant.

Results: In studying data, menarche age $(\mathrm{P}=0.001)$ and menstrual disorder $(\mathrm{P}=0.026)$ had significant difference which was higher in athletic group. The frequency of dysmenorrhea in athletic and non-athletic group did not have significant statistical difference $(\mathrm{P}=0.39)$ while the analgesic consumption was significantly lower in the athletic group $(\mathrm{P}=0.001)$.

Conclusion: This study showed that sport can improve dysmenorrhea and decrease the need for analgesic for improving the dysmenorrhea among the people. Meanwhile, it is necessary to pay more attention to nutrition which is one of the important reasons of delayed menarche and menstrual disorder.

Keywords: Menarche, Menstrual Regularity, Dysmenorrhea, Analgesic, Athlete
\end{abstract}

\section{Introduction}

Along with ever-increasing growth and development of sport, the women's sport and their participation in recreational and competition activities has gained much attention by scientific societies. Sport has many advantages for all people and also for women. Though intense exercise especially weight sports (gymnastic and martial arts) and endurance exercises are accompanied with a series of dangers for women athletes (1). One of these problems is sport activity and their menstrual cycle. This has been studied by many researchers and unfortunately there are many questions and ambiguities about women's sport which shall be solved by doing extensive researches (2). The menstrual period is a regular period that it's duration is 28 days in average. Any state except this regular state of menstrual period is named disorder (3). Menarche is considered as starting the first menstrual period and depends on several factors such as physical activity, nutritional status, height and genetic factors (4). The menarche age is different, while it is in
$12-13$ years old in average $(5,6)$. The proper percent body fat for menarche among girls is at least $17 \%$ (7). $22 \%$ lipid out of the body weight is necessary for a normal menstrual and lack of weight for $10-15 \%$ causes decreasing the body fat and unnatural menstrual $(8,9)$. Elite women especially runners and ballet athletes are very good subjects for the hypothesis on the relationship between body fat and menstrual disorders. In a group of Ballet who had been studied by Frisch, 30\% were suffered from irregular cycles (10). The menstrual disorders like delayed menarche are different due to type of sport and level of matches (11). Intense and prolong exercise and that type of sports which causes losing weight by reducing body fat and increasing mental stresses, expressed as potential factors of menstrual disorders and delayed menarche and makes some other problems such as osteoporosis among women heroes $(12,13)$. Dysmenorrhea (painful menstruation) is one of the most common problems in women that divided into two types of primary (without pelvic pathologic condition) and secondary dysmenorrheal (occurred

Received 17 April 2014, Revised 4 May 2014, Accepted 25 June 2014, Available online 20 July 2014

${ }^{1}$ Faculty of Physical Education, Central Tehran Branch, Islamic Azad University, Tehran, Iran. ${ }^{2}$ School of Nursing and Midwifery, Tabriz University of Medical Sciences, Tabriz, Iran. ${ }^{3}$ Islamic Azad University of Tabriz, Tabriz, Iran.

*Corresponding Author: Ladan Zoodfekr, Islamic Azad University of Tabriz, Tabriz, Iran. Tel: +989144063765,

Email: ladan_zoodfekr@yahoo.com 
related to pathologic states) $(14,15)$. There are different statistics about the incidence of this complication (16). In Iran, the spread of dysmenorrhea is reported among 74-85.5\% of girls (17). Dysmenorrhea treatment includes non steroidal anti-inflammatory drugs (NSAID), Oral Contraceptive Pills (OCP), Acupressure, and medicinal plants (18). Continuous consumption of these drugs can have side effects like depression, nerve damages, inflammation, and skin redness (18). One of the methods for relieve dysmenorrhea which lacks side effects is sport and physical activity. In several studies, aerobic and stretching exercises are introduced as suitable sports for improvement dysmenorrhea (19). Dysmenorrhea may be seen less among women who are active physically compared to the inactive women (20). Several researchers believe that doing exercise for more than three times a week leads to less reporting the dysmenorrhea physical symptoms during menstrual period among active women compared to sedentary women. Saadatabadi et al. showed that doing tensile exercises lead to recovery of primary dysmenorrhea symptoms (16). There was relationship between daily stresses with dysmenorrhea. Sport reducing stress and controlling the chemical changes in the immunity system (21) conflict to interest. Snce most of the researches about menstrual cycle are about elite women, this study try to check menstrual disorders in physical education students to know that if mediocre exercise has any good or bad effect on menstrual cycles or not?

\section{Material and Methods}

This study is a casual-comparative one which was done in 2010 on 360 girl students in 18-28 years old majoring in medicine and non-medicine at the universities of Tabriz. The students suffering from chronic diseases, mental disorders, the subjects consuming contraceptive pills and married students were excluded from the study. A questionnaire including public questions, menstrual and sport questions of the samples was used in this study for gathering the required data. Visual analogue scale (VAS) was used for studying dysmenorrhea. The researcher referred to the vice chancellor of student services of the universities for gathering data related to the number of girl students at University of Tabriz and Tabriz University of Medical Sciences. 360 subjects were chosen from 17 schools of these universities as the sample. Then the current sample was divided into two groups of athlete and non-athlete groups (180 subjects in each group). For studying data, descriptive and inferential statistics (MannWhiteny $U$ and Chi-square) and also Excel and SPSS 16 were used. $\mathrm{P}<0.05$ was considered as significant.

\section{Results}

The mean of age and BMI in the athletic group was $21.37 \pm 4.34$ years old and $20.04 \pm 3.04 \mathrm{~kg} / \mathrm{m}^{2}$ and it was $20.75 \pm 2.12$ years old and $21.59 \pm 3.09 \mathrm{~kg} / \mathrm{m}^{2}$ among the non-athletic group. The mean of menarche age among the athletes and non- athletes respectively were $13.91 \pm 1.42$ and $13.40 \pm 1.34$, and such difference was significant statistically ( $\mathrm{P}=0.001$; Table 1$)$. Regarding the regularity of menstrual cycles among athletes and non-athletes, there was significant difference and such irregularity in the athletic group more than non-athletic group $(\mathrm{P}=0.026$; Table 2). The number of person suffered from dysmenorrhea among the athletic and non-athletic group does not have statistically significant difference $(\mathrm{P}=0.39$; Table 3). The drug consumption for pain relief and dysmenorrhea symptoms between two groups showed significant difference $(\mathrm{P}=0.001$, Table 4 , Figure 1$)$.

\section{Discussion}

The mean of menarche age for athletes was $13.91 \pm 1.42$ and it was $13.40 \pm 1.34$ for non-athletes. Menarche age is significantly higher in athletes compared to non-athletes $(\mathrm{P}=0.001)$. This finding is consistent with the results of researches by Dušek, Klentrou et al, and Markou et al. $(9,21,22)$. The results of researches by these scientists indicate that menarche age among championship athletes who did exercises before puberty is higher than the nonathletes. In the current study, it is possible that those who are classified as athletes, did exercises before puberty age and such exercising causes reducing the body fat and creating stress in the person and all of these factors are effective on menarche age (10). Regarding the regularity in menstrual cycles (it means the duration of one cycle to the other is $28 \pm 7$ days), there was no significant difference among the athletes and non-athletes and such irregularity was significantly higher among the athlete group $(\mathrm{P}=0.026)$. This indicates that sport may create

Table 1. Results of menarche age between athlete and nonathletes.

\begin{tabular}{lll}
\hline \multirow{2}{*}{ Mean } & Athletes(180) & 200.97 \\
\cline { 2 - 3 } & Non Athletes(180) & 160.03 \\
\hline Mann-Whitney U & 125.15 \\
Z & -3.831 \\
$P$ & & $0.001^{*}$ \\
\hline
\end{tabular}

Table 2. Regularity of menstrual cycles among athletic and nonathletes.

\begin{tabular}{lcccc}
\hline Index & $\begin{array}{c}\text { Observed } \\
\text { frequency }\end{array}$ & $\begin{array}{c}\text { Observed } \\
\text { frequency }\end{array}$ & Chi-Square & P \\
\hline Group & Regular & Irregular & & \\
Athlete & $128(71.11 \%)$ & $52(28.88 \%)$ & 4.95 & $0.026^{*}$ \\
$\begin{array}{l}\text { Non- } \\
\text { athlete }\end{array}$ & $146(81.11 \%)$ & $34(18.88 \%)$ & & \\
\hline
\end{tabular}

Table 3. Results of frequency of dysmorrhea age between athlete and non-athletes.

\begin{tabular}{llll}
\hline Group & With dysmenorrhea & $\begin{array}{l}\text { Without } \\
\text { dysmenorrhea }\end{array}$ & P \\
\hline Athlete & $71(39.44 \%)$ & $109(60.55 \%)$ & 0.392 \\
Non-athlete & $79(43.88 \%)$ & $101(56.11 \%)$ & \\
\hline
\end{tabular}




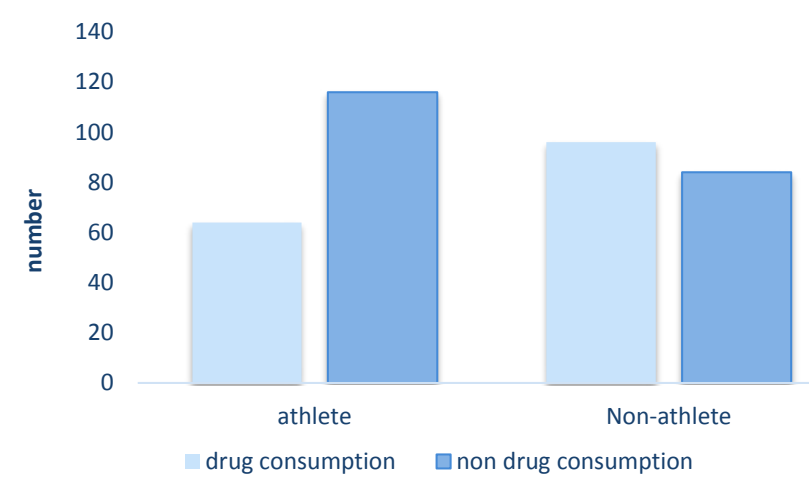

Figure 1. Drug consumption between athlete and non-athletes.

more serious disorders such as Oligomenorrhea or Amenorrhea among athletes which certainly be recovered by discontinuing or reducing the intensity of exercises and proper nutrition during heavy exercises (23). In the current study, the incidence of dysmenorrhea is higher among non-athletes compared to athletes though such difference was not statistically significant $(\mathrm{P}=0.39)$ which was inconsistent to the study by Saadatabadi et al (16), Shavandi et al. (18) and Dušek (9) and such difference can be resulted from the type of sport that people has done in different studies. Saadatabadi et al. (16) and Shavandi et al. (18) showed that all the research subjects has done stretching and isometric exercises that these can cause difference in the results of studies, since these exercises can increase the uterus blood circulation and therefore reduce the dysmenorrhea (19). While in current study, only $0.8 \%$ of the research subjects has done stretching exercises like gymnastic. Dušek's study was done on athletic elites while in the current study, most of the subjects did exercises normally which can be one of the reasons of contradiction among the results of study by Dušek with the current study. Therefore, we can conclude that dysmenorrhea is aggregated or reduced upon being influenced by level, intensity and type of sport. The availability of little and low incidence of dysmenorrhea among the athletes may be due to increasing the threshold of pain by athletes and therefore increasing the pain tolerance by athletes $(19,24)$. Meanwhile, less consumption of NSAID drugs and analgesic for solving pains resulted from dysmenorrhea is less among athletes which can be resulted from the highness of the threshold of pain among athletic group. According to different studies, the endurance exercises and submaximal exercises can increase the threshold and pain tolerance $(25,26)$. The endurance exercises and submaximal exercises can increase the threshold and pain tolerance $(25,26)$. In this study, the author could not supervise on the amount and intensity of exercises by students and also their nutrition which can be considered as the limitation of this study. Meanwhile, economic, cultural factors and the academic status are effective on dysmenorrheal (27).

\section{Conclusion}

In the current study, the researcher controlled the academic status while she could not control the economic and cultural levels. The results of this research showed that sport in normal range may cause disorders in the menstrual periods. Therefore, the trainers and lecturers of physical education should give necessary notes to the students about nutrition (which is one of the main reasons of menstrual disorders) especially during increasing the intensity of exercise and sport. On the other hand, this research showed that sport may improve dysmenorrhea. Therefore it is necessary to take measures so that the students of other majors could benefit from the advantages of sport and physical activity upon increasing the sport hours within the desired extent.

\section{Ethical issues}

The local ethics committee approved the study.

\section{Conflict of interests}

Authors declare that there is no any conflict of interests.

\section{Acknowledgments}

We would like to thank students of Tabriz University and Tabriz university of Medical Sciences for cooperating with this. This study has been done as a thesis for MA degree of Ladan Zoodfekr of Tehran Azad University Central Branch, Tehran-Iran.

\section{References}

1. Chen HM, Chen ChH. Related Factors and Consequences of Menstrual Distress in Adolescent Girls With Dysmenorrhea. Kaohsiung J Med Sci 2005; 21:121-7.

2. Williams NI, McArthur JW, Turnbull BA, Bullen BA, Skrinar GS, Beitins IZ, et al . Effects of follicular phase exercise on luteinizing hormone pulse characteristics in sedentary eumenorrhoeic women. Clin Endocrinol 1994; 41:787-794

3. Gary Cunningham F, Norman F, Gant Kenneth J, Leveno Larry C, John C, Hauth Katarine D. Williams Obstetrics. 2nd ed. New York: McGraw-Hill; 2001. p. 68-77.

4. Uche-Nwachi EO, Odekunle A, Gray J, Bethel T, Burrows Y, Carter J, et al. Mean Age of Menarche in Trinidad and Its Relationship to Body Mass Index, Ethinicity and Mothers Age of Menarche. OnLine Journal of Biological Sciences 2007; 7 (2): 66-71

5. Daniel Goon T, Abel Toriola L, Uever J, Wuam S, Olutoyin Toriola M. Growth status and menarcheal age among adolescent school girls in Wannune, Benue State, Nigeria. BMC Pediatr 2010; 10:60

6. Awdishu S, Williams NI, Laredo Sh, Souza MD. Oligomenorrhoea in Exercising Women. Sports Med 2009; 39 (12): 1055-1069.

7. Paul Kaplowitz B. Link Between Body Fat and the Timing of Puberty. Pediatrics 2008;121; 208-217.

8. Baker BL, Birch LL, Trost SG, Davison KK.. Advanced Pubertal Status at Age 11 and Lower Physical Activity in Adolescent Girls. J Pediatr 2007; 151(5): 488-493. 
9. Dušek T. Influence of High Intensity Training on Menstrual Cycle Disorders in Athletes. Croat Med J 2001;42(1):79-82.

10. Raymond-Barker P, Petroczi A, Quested E. Assessment of nutritional knowledge in female athletes susceptible to the Female Athlete Triad syndrome. J Occup Med Toxicol 2007;2:10.

11. Morgenthal AP. Female athlete triad. J Chiropr Med 2002; 3(1):97-106

12. Christo K, Prabhakaran R, Lamparello B, Cord J, Miller KK, Goldstein MA, et al. Bone Metabolism in Adolescent Athletes With Amenorrhea, Athletes With Eumenorrhea, and Control Subjects. Pediatrics 2008;121:1127-1136.

13. Borgen JS, Torstveit MK. The female football player, disordered eating, menstrual function and bone health. Br J Sports Med 2007;41(I): 68-72

14. Abbaspour Z, Rostami M, Najjar S. The Effect of Exercise on Primary Dysmenorrhea. J Res Health Sci 2004;4(2):26-31.

15. Durain D. Primary Dysmenorrhea, Assessment and Management Update. J Midwifery Womens Health 2004;49(6):520-8.

16. Sadatabadi F, Bambaichi E, Esfarjai F. The effects of 6 weeks Flexibility Exercises on dysmenorrhea. J Esfahan Univ Med Sci 2010; 109: 401-407.

17. Dolatiyan M, Jafari h, Afrakhte M, Taleban F, Gachkar L. Study the effect of Fish oil capsules on primary dysmenorrhea. J Zanjan Univ Med Sci 2004; 47: 7-13.

18. Shavandi N, Soltani F. The effects of a period of isometric Exercises on primary dysmenorrhea. J Arak Univ Med Sci 2010; 13(1): 71-77.

19. Rahmani niya F. Hojjati Z. women, sport and fitness.1st ed. Tehran:Bamdad ketab;2004. p.90-101
20. Klentrou P, Plyley M. Onset of puberty, menstrual frequency and body fat in elite rhythmic gymnasts compared with normal controls. Br J Sports Med 2003;37:490-494

21. Markou KB, Mylonas $\mathrm{P}$, Theodoropoulou A, Kontogiannis A, Leglise M, Vagenakis AG, et al. The Influence of Intensive Physical Exercise on Bone Acquisition in Adolescent Elite Female and Male Artistic Gymnasts. J Clin Endocrinol Metab 2004;89(9):4383-7.

22. Dadgostar H, Razi M, Aleyasin A, Alenabi T, Dahaghin S. The relation between athletic sports and prevalence of amenorrhea and oligomenorrhea in Iranian female athletes. Sports Med Arthrosc Rehabil Ther Technol 2009;1(1):1-16.

23. Locke RJ, Warren MR. What is the effect of exercise on primary dysmenorrhea. Br J Sports Med 1999; 33:227.

24. Gurevich M, Kohn PM, Davis C. Exercise-induced analgesia and the role of reactivity in pain sensitivity. J Sports Sci 1994;12(6):549-59.

25. Krmy RJ, Linder H. Exercise is linked to reductions in anxiety but not premenstrual syndrome in women with prospectively-assessed symptoms. Psychology, Health \& Medicine 1998; 3:211-222.

26. Marvan L, Escobedo CR. Premenstrual Symptomatology: Role of Prior Knowledge About Premenstrual Syndrome. Psychosom Med. 1999 MarApr;61(2):163-7.

27. Torstveit MK, Borgen J. Participation in leanness sports but not training volume is associated with menstrual dysfunction: a national survey of 1276 elite athletes and controls. Br J Sports Med 2005; 39:141147.

Copyright (c) 2014 The Author(s); This is an open-access article distributed under the terms of the Creative Commons Attribution License (http://creativecommons.org/licenses/by/4.0), which permits unrestricted use, distribution, and reproduction in any medium, provided the original work is properly cited. 